\title{
TOOLS FOR MANAGING REFERENCES IN CLASS PROJECTS AND SCIENTIFIC WORKS
}

\author{
Beatriz Andres, Raul Poler, Manuel Diaz-Madroñero \\ Research Centre on Production Management and Engineering (CIGIP). Universitat \\ Politècnica de València (UPV) (SPAIN)
}

\begin{abstract}
This paper presents a set of tools to manage references, for its application in class projects, in the university context, and in scientific works. The main aim of this paper is to provide a set of tools to support university students and researchers to store all their research, and sort all their references, documents and notes in one place. This paper is an extension of the paper "Adjustment of students to be future researchers: The importance of a systematic literature review methodology for MSC students" [1] that proposes a guideline to help students to systematically perform the literature review phase in the research work. The work developed in the present paper, focuses on collecting, managing and treating the results through building a personalised database, proposing in a more extended way a set of tools to manage references of the research work performed in the systematic literature review.
\end{abstract}

Keywords: references management, literature review, PhD students, MSC students, research, citation.

\section{INTRODUCTION}

The literature review is the initial phase of any research, and is performed by students and researchers with the aim of acquiring the knowledge of the state of the art of the topic and area researched. The literature review enables students and researches to be sure no one has already written their dissertation (see Figure 1). Moreover, conducting a systematic literature review allows to: (i) deeply know a particular study; (ii) formulate appropriate hypothesis; (iii) raise proper research questions; (iv) identify the gaps that will allow to propose original contributions in the work developed; and (v) justify the research work [1]. Knowing how to manage the bibliography in the literature review phase is an fundamental competence for any student or researcher. Building a reference database will help in the task of managing the works collected when carrying out the state of the art.

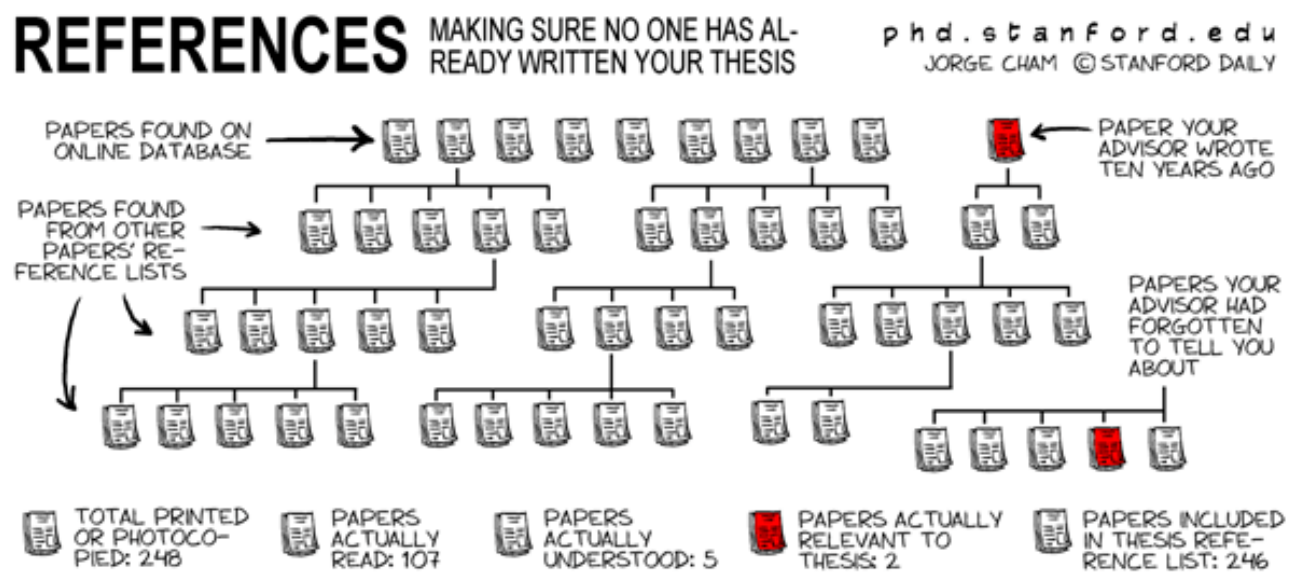

Figure 1. References: Make sure no one has already written your thesis [2].

The main aim of this paper is to provide a set of tools to support university students and researchers to store all their research, and sort all their references, documents and notes in one place. This paper is an extension of the paper "Adjustment of students to be future researchers: The importance of a systematic literature review methodology for MSC students" [1] that proposes a guideline to help students to systematically perform the literature review phase in the research work. The provided systematic literature review methodology developed by [1], consists of six phases (see Figure 2): 
(i) Identifying the research area and the period of study: This phase allows detecting the research problem and defining research objectives. It is also identified the period of time in which the literature review is performed.

(ii) Selecting the information sources: Journals, conference proceedings, thesis, books internet, reports, studies, newspapers, government agencies, enterprises, etc.

(iii) Carrying out the research: establish the criteria that allow filter the relevant references that fill the pursued goal (field of study and period of analysis).

(iv) Managing and treating the results through building a personalised database.

(v) Analysing the results: The analysis performed with the finally selected papers depends on the purpose of the investigation

(vi) Writing the interesting features of the literature reviewed in a synthesis: Integrate the ideas that were previously dispersed and turn them into a coherent text, clarifying concepts, introducing new ones into the subject and giving a personal perspective. Finally the gaps in the area under study are to be identified in order to fill them and provide original contributions.

- Identify the study area in the period
- Selection of the information sources
- Conduct the research
- Management of results
- Analysis of results
- Write the results from research

Figure 2. Literature Review Guideline [1], adapted from [3].

Until the students do not start with the work of performing the literature review, do not realize the difficulty of managing hundreds of references. Reference management tools work by creating a database with all the bibliography found. When the authors want to write the results of the literature review, they only have to link the document with the database, which contains all the references to be cited in the document.

Recalling to the Literature Review Guideline, the work developed in the present paper, focuses on phase iv proposing in a more extended way a set of tools to manage references and building a personalised database of the research work performed in the systematic literature review. In order to deal with the proposed objective, this paper is organised in the following sections

\section{BIBLIOGRAPHY AND CITATION TOOLS FOR EDUCATION AND RESEARCH}

Students are not completely aware of the importance of carrying out an organized and systematic literature review. The first step, for any university teacher, is to spread, among its students, the relevance of performing an accurate work in when analysing the state of the art of any research topic. At the degree level, university students have not had to do much on performing states of the art, managing references and citing. The role of the teacher is, at this stage, very important when putting across the relevance of good sourcing, plagiarism, citing and acquire a comprehensive background of the research concepts.

In the specific stage of managing references, a good organization of them will facilitate students and researchers on the work to be performed in the literature review. In the light of this, the Internet offers an abundance of online citation tools, from the extremely easy to use, to ones that require more research on the part of the user. Moreover, there is a wide range of tools that makes it easy for students and researchers to generate manage references and generate citations and in different style formats, with the main aim of completing the literature review phase in any research work. 
This section proposes and describes a set of tools that are considered interesting for managing the research and sorting all the references collected when performing the research work. Table 1 presents an analysis of the characteristics of each identified bibliography and citation tool. The list of tools is disposed in an alphabetical order. Characteristics such as (i) PDF management; (ii) exportation electronic databases connection, including Scopus (http://www.scopus.com/) or scholar Google (https://scholar.google.es/); (iii) compatibility with operation systems; (iv) citation stiles offered; (v) open-source supported; (vi) easy to use; (vii) plagiarism checker; and (viii) collaboration supported for teams, are analysed.

Table 1. Reference Management Tools.

\begin{tabular}{|c|c|c|c|c|c|c|c|c|c|}
\hline $\begin{array}{l}\text { Reference } \\
\text { Tool }\end{array}$ & $\begin{array}{c}\text { PDF } \\
\text { Managem } \\
\text { ent }\end{array}$ & $\begin{array}{l}\text { Exportation/ } \\
\text { Connection }\end{array}$ & Platform & \begin{tabular}{|c} 
Word \\
processor \\
integration
\end{tabular} & $\begin{array}{l}\text { Citation } \\
\text { Stiles }\end{array}$ & Source & $\begin{array}{c}\text { Easy to } \\
\text { use }\end{array}$ & $\begin{array}{c}\text { Plagiarism } \\
\text { checker }\end{array}$ & $\begin{array}{c}\text { Collabora } \\
\text { tion }\end{array}$ \\
\hline BibMe [4] & - & - & Web & - & $\begin{array}{c}\text { MLA } \\
\text { APA } \\
\text { Chicago } \\
\text { Turabian }\end{array}$ & Licenced & 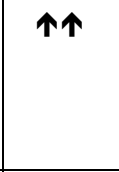 & $\nabla$ & No \\
\hline $\begin{array}{c}\text { Citation } \\
\text { Machine [5] }\end{array}$ & - & - & Web & - & $\begin{array}{c}\text { MLA } \\
\text { APA } \\
\text { Chicago } \\
\text { Turabian }\end{array}$ & Licenced & 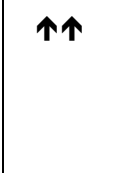 & $\nabla$ & No \\
\hline Citavi [6] & $\square$ & - & Windows & $\begin{array}{l}\text { MS Word } \\
\text { LibreOffice }\end{array}$ & $\begin{array}{c}6000 \text { citati } \\
\text { on styles }\end{array}$ & $\begin{array}{c}\text { Open } \\
\text { Licenced }\end{array}$ & $\uparrow$ & - & Yes \\
\hline $\begin{array}{c}\text { Cite this for me } \\
{[7]}\end{array}$ & $\nabla$ & - & Web & MS Word & $\begin{array}{c}\text { APA } \\
\text { MLA } \\
\text { Chicago } \\
\text { Harvard } \\
\end{array}$ & $\begin{array}{c}\text { Open } \\
\text { Licenced }\end{array}$ & $\uparrow$ & - & No \\
\hline CiteFast [8] & - & - & Web & - & $\begin{array}{c}\text { APA } \\
\text { MLA } \\
\text { Chicago }\end{array}$ & Open & 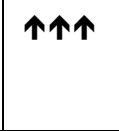 & - & No \\
\hline Docear [9] & $\nabla$ & - & $\begin{array}{c}\text { Windows } \\
\text { MAC OS X } \\
\text { Linux } \\
\text { Web } \\
\end{array}$ & $\begin{array}{l}\text { MS Word } \\
\text { (Windows) }\end{array}$ & \begin{tabular}{|} 
Citation \\
Style \\
Language \\
(CSL)
\end{tabular} & Open & $\uparrow$ & - & No \\
\hline Easy Bib [10] & - & Google & Web & - & $\begin{array}{c}\text { MLA } \\
\text { APA } \\
\text { Chicago }\end{array}$ & Open & $\uparrow$ & - & No \\
\hline EndNote [11] & $\nabla$ & $\begin{array}{c}\text { ScienceDirect } \\
\text { Scholar } \\
\text { Google }\end{array}$ & $\begin{array}{c}\text { Windows } \\
\text { MAC OS X } \\
\text { Web }\end{array}$ & $\begin{array}{l}\text { MS Word } \\
\text { (Windows) } \\
\text { LibreOffice }\end{array}$ & $\begin{array}{c}\text { MLA } \\
\text { APA } \\
\text { Chicago }\end{array}$ & $\begin{array}{l}\text { Licenced / } \\
\text { Open }\end{array}$ & 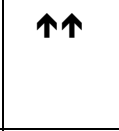 & - & Yes \\
\hline Mendeley [12] & $\square$ & $\begin{array}{c}\text { ScienceDirect } \\
\text { Scopus }\end{array}$ & $\begin{array}{c}\text { Windows } \\
\text { MAC OS X } \\
\text { Linux } \\
\text { Web } \\
\end{array}$ & $\begin{array}{l}\text { MS Word } \\
\text { (Windows } \\
\text { \& Mac) } \\
\text { LibreOffice }\end{array}$ & $\begin{array}{c}\text { MLA } \\
\text { APA } \\
\text { Chicago } \\
\text { etc. }\end{array}$ & Open & 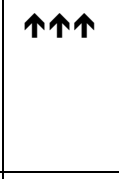 & - & Yes \\
\hline Ottobib [13] & - & Google & Web & - & $\begin{array}{c}\text { MLA } \\
\text { APA } \\
\text { Chicago } \\
\text { BibTeX } \\
\text { Wikipedia }\end{array}$ & Open & $\uparrow$ & - & No \\
\hline ProCite [14] & $\nabla$ & $\begin{array}{c}\text { ScienceDirect } \\
\text { Scholar } \\
\text { Google }\end{array}$ & $\begin{array}{l}\text { Windows } \\
\text { MAC OS X }\end{array}$ & $\begin{array}{l}\text { MS Word } \\
\text { (Windows) }\end{array}$ & $\begin{array}{c}\text { MLA } \\
\text { APA } \\
\text { Chicago }\end{array}$ & $\begin{array}{l}\text { Licenced / } \\
\text { Open }\end{array}$ & 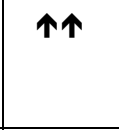 & - & Yes \\
\hline $\begin{array}{c}\text { Recipes4Succe } \\
\text { ss [15] }\end{array}$ & - & Google & Web & - & $\begin{array}{l}\text { APA } \\
\text { MLA }\end{array}$ & Open & $\uparrow$ & - & Yes \\
\hline RefDot [16] & - & $\begin{array}{c}\text { Amazon book } \\
\text { pages }\end{array}$ & Web & - & - & Open & $\uparrow$ & - & No \\
\hline
\end{tabular}




\begin{tabular}{|c|c|c|c|c|c|c|c|c|c|}
\hline $\begin{array}{c}\text { Reference } \\
\text { Tool }\end{array}$ & $\begin{array}{c}\text { PDF } \\
\text { Managem } \\
\text { ent }\end{array}$ & $\begin{array}{c}\text { Exportation/ } \\
\text { Connection }\end{array}$ & Platform & $\begin{array}{c}\text { Word } \\
\text { processor } \\
\text { integration }\end{array}$ & $\begin{array}{c}\text { Citation } \\
\text { Stiles }\end{array}$ & Source & $\begin{array}{c}\text { Easy to } \\
\text { use }\end{array}$ & $\begin{array}{c}\text { Plagiarism } \\
\text { checker }\end{array}$ & $\begin{array}{c}\text { Collabora } \\
\text { tion }\end{array}$ \\
\hline $\begin{array}{c}\text { Reference } \\
\text { Manager [17] }\end{array}$ & - & $\begin{array}{c}\text { ScienceDirect } \\
\text { Scopus } \\
\text { Scholar } \\
\text { Google }\end{array}$ & Windows & MS Word & $\begin{array}{c}\text { MLA } \\
\text { APA } \\
\text { Chicago }\end{array}$ & $\begin{array}{c}\text { Licenced / } \\
\text { Open }\end{array}$ & $\uparrow$ & - & Yes \\
\hline RefWorks [18] & $\nabla$ & $\begin{array}{c}\text { ScienceDirect } \\
\text { Scopus } \\
\text { Scholar } \\
\text { Google }\end{array}$ & $\begin{array}{c}\text { Windows } \\
\text { Linux } \\
\text { Web }\end{array}$ & $\begin{array}{c}\text { MS Word } \\
\text { (Windows) }\end{array}$ & $\begin{array}{c}\text { APA } \\
\text { MLA } \\
\text { Chicago } \\
\text { etc. }\end{array}$ & Licenced & $\uparrow \uparrow$ & - & Yes \\
\hline Zotero [19] & $\square$ & - & $\begin{array}{c}\text { Windows } \\
\text { MAC OS X } \\
\text { Linux }\end{array}$ & $\begin{array}{c}\text { MS Word } \\
\text { (Windows) } \\
\text { LibreOffice }\end{array}$ & $\begin{array}{c}\text { Citation } \\
\text { Style } \\
\text { Language } \\
\text { (CSL) }\end{array}$ & Open & $\uparrow$ & - & Yes \\
\hline
\end{tabular}

According to the provided matrix an assessment process will be performed with the main aim of selecting of the most appropriate tools.

\section{PROPOSED TOOLS FOR MANAGING REFERENCES}

In section 3, three most relevant tools are selected and illustrated with examples. The three selected tools will be (i); EndNote [11] and (ii) Mendeley [12], (iii) RefWorks [18]. These three tools, used for managing bibliography and references, are selected due to its easiness of use and advantages such as: (i) showcase the impact of the researchers work; (ii) share reading lists, references and full-text articles with researchers' network, publicly or privately and create groups to tackle research assignments, share feedback; (iii) search and sort all of the references, documents and notes in one place, and store research securely and access it easily across all the researchers' or students devices; (iv) annotate and add sticky notes to capture thoughts; (v) generate citations and bibliography as writing, in the style of choice; and (vi) compatible with Microsoft Word, LibreOffice and BibTeX. Moreover, Mendely [3] is an open-source online tool compatible with Mac OS and Windows.

\subsection{EndNote}

More than just a reference manager. EndNote moves through the research process as students and researchers search, organize, write, publish and share their collected references (See Figure 3).

EndNote takes the literature search fast and productive, providing an organized research library. Moreover, it collects full-text PDFs and adds your notes and annotations and delivers the famously easy Cite While You Write in Microsoft $₫$ Word. Creates perfectly formatted bibliographies, endnotes and in-text citations. EndNote can be installed and used in Mac $\circledast$ and Windows $®$ equally; and keeps it all synced up - on the researcher desktop, online and on the iPad® app.

EndNote library sharing is not restricted to people within the same firewall or organization. EndNote works from a single reference library with up to 100 people, no matter where they are located or what organization they are affiliated with. The online tool allows to instantly see the history of changes made to the students or researchers shared library with a built-in activity log.

Using EndNote online, allows to find the journals where research is most likely to be accepted based on an analysis of tens of millions of citation connections in Web of Science ${ }^{\mathrm{TM}}$. 


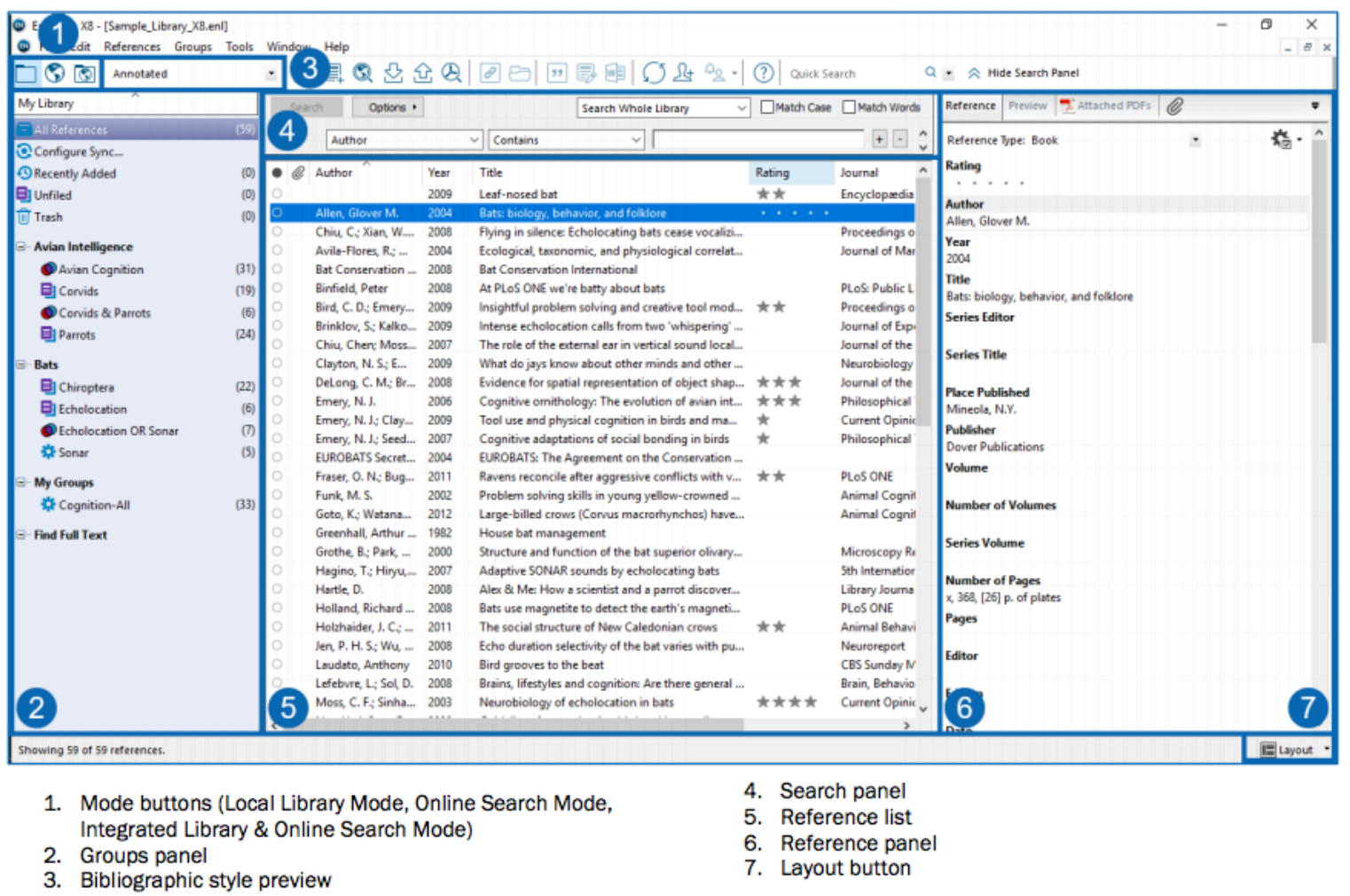

Figure 3. EndNote Menus reference guide screenshot [20].

\subsection{Mendeley}

Mendeley is a desktop and web program produced by Elsevier for managing and sharing research papers, discovering research data and collaborating online (see Figure 4). It combines Mendeley Desktop, a PDF and reference management application (available for Windows, OS X and Linux) and Mendeley for Android and iOS, with Mendeley Web, an online social network for researchers. In this regard, Mendeley allows sharing datasets with collaborators and getting a unique DOI to support accurate citation of your data. Mendeley provides a secure online repository with sharing features.

Mendeley requires the user to store all basic citation data on its servers-storing copies of documents is at the user's discretion. Upon registration, Mendeley provides the user with 2 GB of free web storage space, which is upgradeable at a cost [21].

The main components that make up Mendeley allow to:

Organize - to set up the students or researchers library, move from and/or integrate with other reference management software, create collections, etc. collections \& groups, reference list and document details. If researchers and students have previously been using a different reference management tool such as EndNote Zotero or RefWorks, they can move from that tool to Mendeley.

Manage - cool features that allow you to keep your library up to date. The following tools will help researchers and students to manage their library with Mendeley:

- Watch folder - set up a folder on the computer that automatically imports PDFs into your library. Simply, drag and drop.

- Mark-up (stars, read-unread) - Knowing which articles user already read and marking those that you like the most.

- Synchronize Documents - Synchronize library so that you can have it with you wherever you go.

- Account capacity - Mendeley's free account has limited storage space in the cloud.

- Web importer - A bookmarklet that lets easily import references and articles from within the browser. 
Read and write (i) PDF viewer - Read one or multiple documents within Mendeley Desktop and use the various tools to highlight and annotate your documents; (ii) Citation Plugin - Adding citations to word document is an essential tool when writing your thesis, report, paper. Mendeley Desktop has a plugin available for all major word processors out there.

Collaborate - with colleagues using Mendeley. Working in collaboration is an essential part of research. Therefore, Mendeley have quite a few great features to enable collaborative work.

- Researcher profile - Researchers profile on Mendeley Web. Lists published work and other information that the researchers provide, such as affiliation, areas of research, etc.

- Adding contacts - Connecting with others is essential to collaborate within Mendeley. Therefore, Mendeley shows how you can find and add new contacts.

- Groups - Collaboration within Mendeley is done through groups. There are public and private groups.

Discover - Mendeley helps you find articles critical to your research via automatic recommendations and a searchable database of almost 300 million records.

Participate - Mendeley's development roadmap has been modelled by user's feedback.

Other interesting characteristics are:

- Mendeley Desktop, based on Qt, runs on Windows, Mac and Linux.

- Back-up and synchronization across multiple computers and with a private online account.

- PDF viewer with sticky notes, text highlighting and full-screen reading.

- Full-text search across papers.

- Smart filtering, tagging and automatic PDF file renaming.

- Import of documents and research papers from external websites (e.g., PubMed, Google Scholar, Arxiv) via browser bookmarklet.

- BibTeX export/file sync.

- Private groups to collaboratively tag and annotate research papers.

- Public groups to share reading lists.

- Social networking features (newsfeeds, comments, profile pages, etc.).

- Usage-based readership statistics about papers, authors and publications.

- iPhone app.

- iPad app.

- Android app 


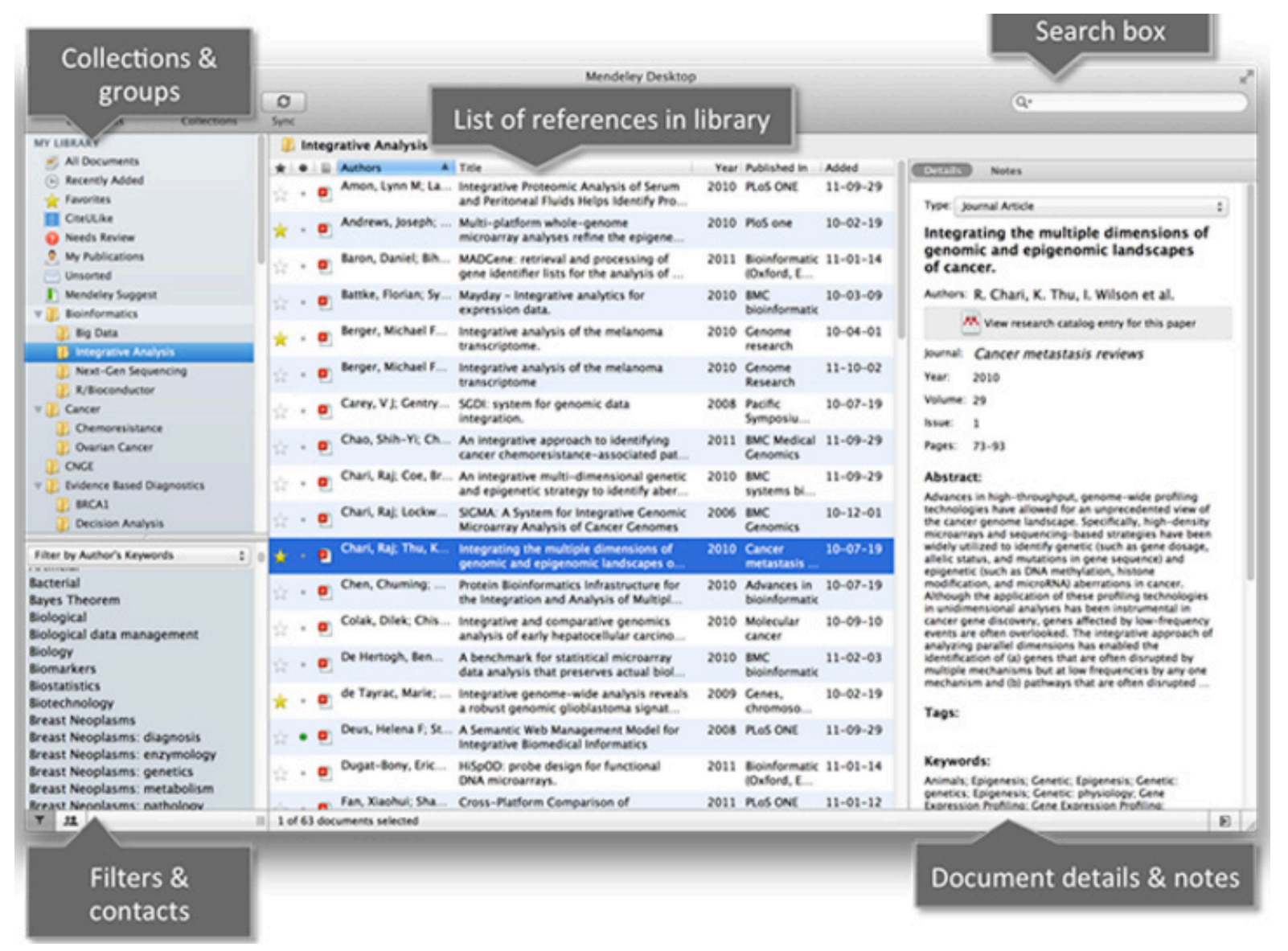

Figure 4. Mendely Desktop.

\subsection{RefWorks}

Refworks is a web-based bibliographic management program that allows students and researchers to (see Figure 5):

- Create a personal bibliographic database.

- Import bibliographic references automatically from numerous databases accessible.

- Organize bibliographic references.

- Exchange bibliographic references via Internet with RefShare

- Format bibliographies and insert them in their original articles.

Characteristics of RefWorks:

- Import data directly

- Import data from saved text files

- Convert references from other bibliographic management products

- Import from RSS feed

- Enter references manually

- Import from catalogues or databases

- Data online

- Attach files to a reference

- Create Folders

- Placing references in folders

- Sort references 
- Edit references globally

- Compare References

- Format the bibliography from a list of references

- Edit or create a bibliographic format

- Write-N-Cite Manuscript

- Bibliography of Write-N-Cite

Idioma | Actualizar perfil | Personalizar | Contáctenos | Refmobile | Salir

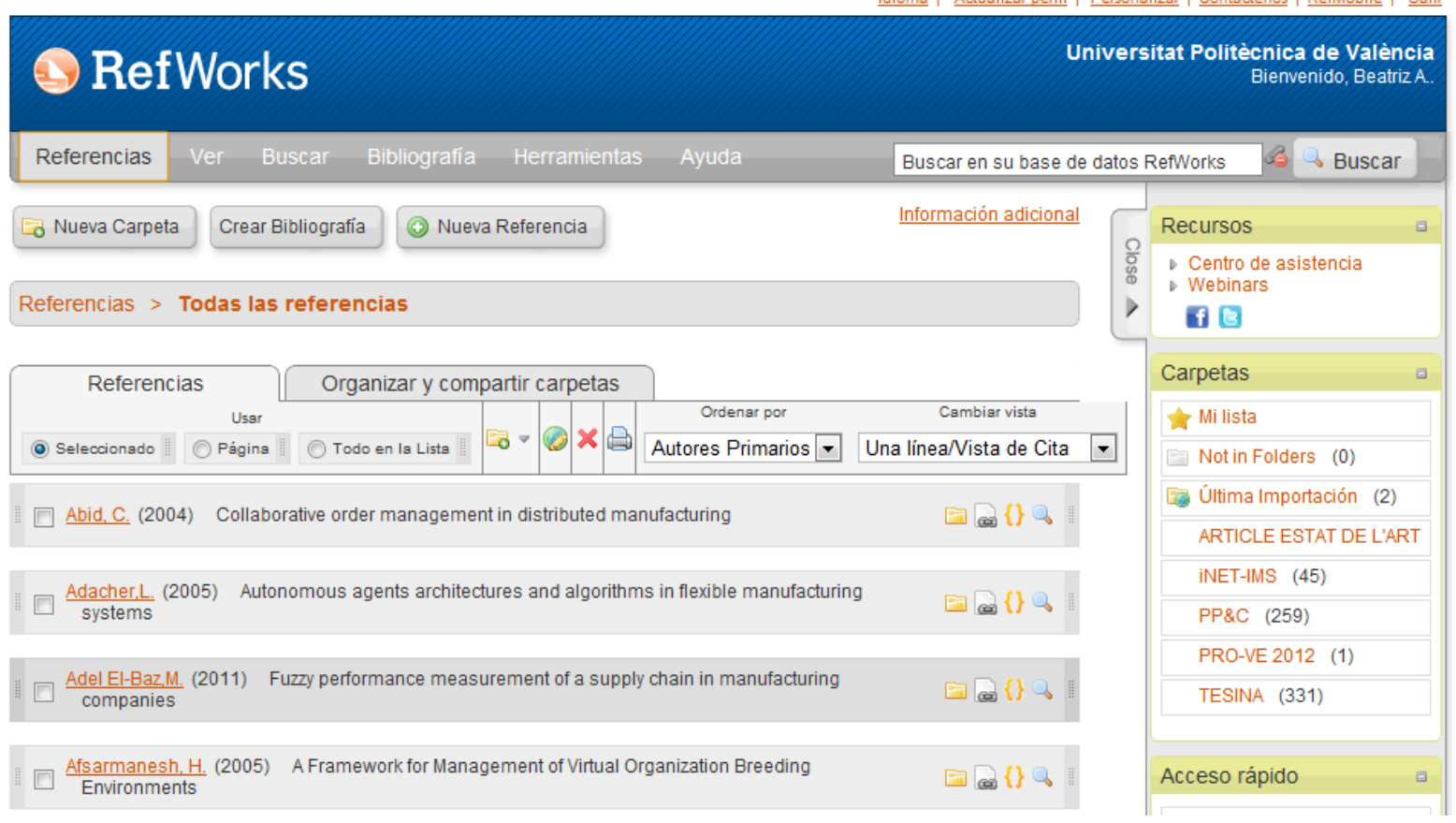

Figure 5. RefWorks Desktop.

With the aim of testing the tools, the researchers of the Research Centre on Production Management and Engineering (acronym in Spanish, CIGIP), of the Universitat Politècnica de València (UPV), have used the identified references management tools in the tasks of literature review, in the H2020 European Project: Cloud Collaborative Manufacturing Networks (C2NET) [22]. In order to introduce the reader, C2NET objective is based on the creation of cloud tools to support optimization of manufacturing networks composed mainly of SMEs and their logistic assets through demand management, production and supply plans, considering the Collaborative Network perspective. Interested readers can access the work of Andres et at. [23], in which an overview of the project, as well as the objectives, and a summary of the results is presented. The task carried out for creating a Taxonomy of optimization and simulation solutions for Manufacturing and Logistics Processes was the one in which the Mendeley reference manager has been tested. The consideration of Mendeley tool has allowed the researchers involved in C2NET project to manage the high amount of references encountered for developing the state of the art task. Accordingly, the researchers involved have tested the easy of use and confirmed the advantages associated with the tool to manage references.

In this regard, Mendeley, as one of the proposed tools, will serve not only to students but also to researchers, being powerful enough to manage references and collaborate when performing literature review tasks.

\section{CONCLUSIONS}

This paper is an extension of the paper "Adjustment of students to be future researchers: The importance of a systematic literature review methodology for MSC students" [1] that proposes a guideline to help students to systematically perform the literature review phase in the research work. The provided systematic literature review methodology developed by [1], consists of six phases: (i) identifying the research area and the period of study; (ii) selecting the information sources, (iii) 
carrying out the research, (iv) managing and treating the results through building a personalised database, (v) analysing the results, and (vi) writing the interesting features of the literature reviewed in a synthesis. The work developed in the present paper, focuses on phase iv proposing in a more extended way a set of tools to manage references and building a personalised database of the research work performed in the systematic literature review.

In this paper, a study of the most relevant tools for managing references is presented, considering some the most valuable characteristics for students and researchers, when performing the literature review work. The assessment performed has allowed selecting a set of three tools to manage references in the context of degree and PhD students, and researchers. EndNote and Mendeley are open source tools, while RefWorks is a licenced tool; nevertheless, its easiness of use and the advantages associated has led the authors to also take into account this tool for managing references. It must be said that some universities provide the licences of RefWorks tools for their students, teachers and researchers.

EndNote and Mendeley can be used in both Mac OS X and Windows. In the three mentioned reference management tools, collaboration is an embedded characteristic. In the current global research environments, high amount of knowledge is produced every day, and the amount of references to be managed by students and researchers exponentially increases. For that reason the consideration of using reference management tools is considered so important. To this extent, students and researchers will benefit from online tools and applications, and will be supported by the centralisation of the research work in one place when carrying out the state of the art of their research work. Mendeley reference manager tool has been tested in the H2020 European Project: Cloud Collaborative Manufacturing Networks (C2NET).

\section{ACKNOWLEDGEMENTS}

The research leading to these results has received funding from European Community's H2020 Programme (H2020/2014-2020) under grant agreement $n^{\circ} 636909$, "Cloud Collaborative Manufacturing Networks (C2NET)".

\section{REFERENCES}

[1] Andres, B. and Poler, R. (2014) Adjustment of students to be future researchers: The importance of a systematic literature review methodology for MSC students. ICERI Proceedings, pp 3125-3133. ISBN: 978-84-617-2484-0.

[2] Jorge Cham (2016) References: Making sure no one has already written your thesis. Retrieved in December 2016, form: http://www.phdcomics.com/comics/archive. php?comicid=286

[3] Medina-López, C., Marín-García, J.A., Alfalla-Luque, R. (2010) Una propuesta metodológica para la realización de Búsquedas sistemáticas de bibliografía. (A methodological proposal for the systematic literature review). Working Papers on Operations Management Vol 1(2), pp.1330.

[4] http://www.bibme.org/?utm_campaign=elearningindustry.com\&utm_source=\%2F12-best-freeonline-bibliography-and-citation-tools\&utm_medium=link

[5] http://www.citationmachine.net/?utm_campaign=elearningindustry.com\&utm_source=\%2F12best-free-online-bibliography-and-citation-tools\&utm_medium=link

[6] https://www.citavi.com/en/index.html?utm_campaign=elearningindustry.com\&utm_source=\%2F 12-best-free-online-bibliography-and-citation-tools\&utm_medium=link

[7] http://www.citethisforme.com/es

[8] http://www.citefast.com/titlepage.php

[9] http://www.docear.org/

[10] http://www.easybib.com/?utm_campaign=elearningindustry.com\&utm_source=\%2F12-bestfree-online-bibliography-and-citation-tools\&utm_medium=link

[11] http://endnote.com/

[12] https://www.mendeley.com/ 
[13] http://www.ottobib.com/?utm_campaign=elearningindustry.com\&utm_source=\%2F12-best-freeonline-bibliography-and-citation-tools\&utm_medium=link

[14] http://endnote.com/downloads/filter/procite-ris

[15] http://recipes.tech4learning.com/index.php?v=pl\&page_ac=view\&type=tools\&tool=bibliography maker\&utm_campaign=elearningindustry.com\&utm_source=\%2F12-best-free-onlinebibliography-and-citation-tools\&utm_medium=link

[16] https://chrome.google.com/webstore/detail/refdot/hdhekmbccpnbffkkdoinkjmggbcpcflo?utm_ca mpaign=elearningindustry.com\&utm_source=/12-best-free-online-bibliography-and-citationtools\&utm_medium=link

[17] http://referencemanager.com/

[18] https://www.refworks.com/es/

[19] https://www.zotero.org/

[20] http://dewey.thomsonreuters.com/training/Little\%20Book/EndNote_Menus_Reference_Guide.p df

[21] https://es.wikipedia.org/wiki/Mendeley

[22] C2NET (2017) Cloud Collaborative Manufacturing Networks http://c2net-project.eu/

[23] Andres, B., Sanchis, and Poler, R. (2016) A Cloud Platform to support Collaboration in Supply Networks. International Journal of Production Management and Engineering 4 (1), pp. 5-13. 